\title{
EVALUATION OF SILICON OIL EVACUATION PROCEDURE IN CIPTO MANGUNKUSUMO HOSPITAL INDONESIA
}

Triwijayanti $^{1}$, Ari Djatikusumo ${ }^{2}$, Andi Arus Victor ${ }^{2}$, Elvioza ${ }^{2}$, Gitalisa Andayani Adriono ${ }^{2}$, Anggun Rama Yudantha², Mario Marbungaran Hutapea²

${ }^{1}$ Rumah Sakit Umum Daerah Tarakan, Jakarta, Indonesia

2 Vitreoretina Division, Department of Ophthalmology, Faculty of Medicine Universitas Indonesia Cipto Mangunkusumo Hospital, Indonesia

\section{ABSTRACT}

Background: Injection of Silicon oil (SO) is a standard procedure for vitreous replacement in vitrectomy procedure for retinal detachment cases. It acts as a great tamponading agent for reattachment of retinal breaks or retinal detachment. Despite its minor side effect, SO could cause several complications such as cataract, endothelial decompensation, increased intraocular pressure, and secondary glaucoma. Thus needed to be evacuated after the retinal reattachment is stabilized. Following the evacuation procedure, visual acuity is known to be significantly improved. However, some cases show decreased of visual acuity due to retinal redetachment, optic nerve damage due to secondary glaucoma, hypotony, vitreous hemorrhage, expulsive hemorrhage, and cornea abnormality.

Methods: A retrospective descriptive study of retinal detachment patients underwent so evacuation procedure in Cipto Mangunkusumo Hospital, Indonesia from September 2017 until January 2018.

Results: There were seventy-seven cases of retinal detachment undergoes 50 evacuation within the period of September 2017-January 2018. There was an improvement of visual acuity (greater than 6/60) after one month of SO evacuation. Anatomical retinal reattachment was successfully observed in $91 \%$ patient. The most occurring complication after SO evacuation includes secondary glaucoma and retinal redetachment.

Conclusion: SO evacuation is a standard procedure following a vitrectomy in retinal detachment cases. The evacuation procedure yields in positive benefit for patient in term of visual acuity and anatomical structure.

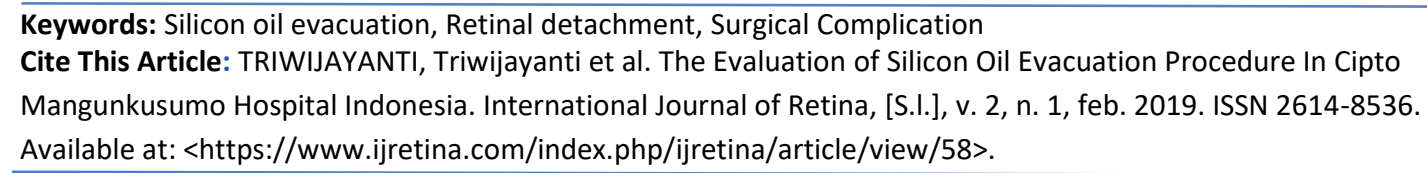

\section{BACKGROUND}

Silicon oil (SO) was introduced by Cibis et al in 1962 as a tamponading agent to manage retinal detachment then Haut et al combined SO with vitrectomy. ${ }^{1,2}$ Nowadays, pars plana

*Correspondence to:

Andi Arus Victor,

Department of Ophthalmology,

Universitas Indonesia,

arvimadao@yahoo.com vitrectomy with SO injection becomes the standard procedure for retinal detachment notably for complex cases of retinal detachment including proliferative vitreoretinopathy, giant tear, tractional retinal detachment, and trauma. ${ }^{3-6}$

$\mathrm{SO}$ is an inert and stable polymer with minimal toxicity reaction and high surface adherence which makes it a good vitreous replacement. In retinal detachment cases, SO covers the surface of detached retina, holds and prevents the fluid to enter the subretinal space. $^{7}$ SO used for vitreoretina surgery has viscosity of 1000 cst or 5000 cst and specific gravity of 0.97 which is less than aqueous humor and vitreous humor thus SO tends to float in vitreous cavity. ${ }^{8}$

The application of SO as a tamponading agent has more benefit compared to gas. Several studies shows that using SO has higher surgical outcome compared to gas. SO is also the more preferable tamponading agent for patients who are a frequent travel and unable to position their head after surgery. 9,10

SO tamponade has several complications and these are endothelial decompensation, cataract, elevated intraocular pressure, and secondary glaucoma. 
Therefore, SO is evacuated after the retinal condition has been stabilized or emulsification has occurred.11 Evacuation procedure is associated with improvement of visual acuity.

However, some studies also found a reduction of visual acuity following evacuation procedure due to retinal redetachment, optic nerve damage due to secondary glaucoma, hypotonic eye, vitreous bleeding, expulsive hemorrhage, and cornea abnormality. ${ }^{12,13}$

\section{METHODS}

This is a retrospective descriptive study of retinal detachmnet patients in Cipto Mangunkusumo Hospital, Indonesia who underwent vitrectomy with SO injection and followed by SO evacuation procedure from the period of September 2017 until January 2018. Written informed consent was obtained from each patient prior to all procedures of silicone oil evacuation in this study.

The inclusion criteria are all retinal detachment patients who underwent SO evacuation in September 2017 until January 2018. The exclusion criteria are patients with unattached retina after vitrectomy with SO injection and patient who has history of past surgical procedure including scleral buckling or gas vitrectomy.

The data was collected from patient's medical record. The collected data are patient's base characteristics, details on SO evacuation procedures, visual acuity pre SO injection and post SO evacuation, intraocular pressure pre SO injection and post SO injection, and complication post SO evacuation. Examination of patient's visual acuity and intraocular pressure was done one month post $\mathrm{SO}$ evacuation.

The collected data were then processed descriptively and all variables presented in the table.

\section{RESULT}

There were eighty-one retinal detachment cases which underwent SO evacuation in the period of September 2017-January 2018. Four cases were excluded from the study due to the previous history of gas vitrectomy or scleral buckling. There were seventy-seven cases were included in the study.

Distribution of patient's characteristics is shown on table 1. The majority of retinal detachment patients are male $67.53 \%$ meanwhile female contributes only $32.47 \%$. Patient tends to be in age $>50$ years old (53.25\%) and only a small number of patients are in age $<30$ years old $(6.49 \%)$. There were $23.38 \%$ of patients who have high myopia status prior to surgery. Patient's status lens prior to SO injection was found to be phakic in $92.21 \%$ of patients and only 6 patients $(7.79 \%)$ who possessed pseudophakic lens
Table 1. Patient's Characteristics

\begin{tabular}{ccc}
\hline Variable & $\begin{array}{c}\text { Frequency } \\
\text { (n) }\end{array}$ & $\begin{array}{c}\text { Percentage } \\
\text { (\%) }\end{array}$ \\
\hline Gender $(\mathrm{n}=77)$ & & \\
Male & 52 & 67.53 \\
Female & 25 & 32.47 \\
Age (n=77) & & \\
$<30$ & 5 & $6.49 \%$ \\
$30-50$ & 31 & $40.26 \%$ \\
$>50$ & 41 & $53.25 \%$ \\
High Myopia & 18 & 23.38 \\
Lens Status & & \\
(n=77) & & \\
Phakic & 71 & 92.21 \\
Pseudophakic & 6 & 7.79
\end{tabular}

Table 2 summarized the indications for SO evacuation procedure. The main indication for SO evacuation was emulsification which occurs on 44 cases (57.14\%). The second most common indication was stable retina reattachment found in 23 cases (29.87\%). The other indication was secondary glaucoma (3 cases) and cataract (9 cases).

Table 2. Indication for SO Evacuation Procedure

\begin{tabular}{lcc}
\hline $\begin{array}{c}\text { SO Evacuation } \\
\text { Indication }\end{array}$ & $\begin{array}{c}\text { Frequency } \\
\text { (n) }\end{array}$ & $\begin{array}{c}\text { Percentage } \\
\text { (\%) }\end{array}$ \\
\hline SO Emulsification & 44 & $57.14 \%$ \\
Secondary Glaucoma & 3 & $3.89 \%$ \\
Cataract & 7 & $9.1 \%$ \\
Retina reattached (>6 & 23 & $29.87 \%$
\end{tabular}

months)

Table 3 describes the SO evacuation procedure and additional surgical procedure. Additional procedures in conjunction with SO evacuation include phacoemulsification, intraocular lenses, endolaser, SO exchange, and vitrectomy. There were 46 patients who underwent SO evacuation only.

\begin{tabular}{lcc}
\multicolumn{1}{c}{ Table 3. SO Evacuation and Additional Surgical Procedure } & $\begin{array}{c}\text { Frequency } \\
\text { (n) }\end{array}$ & $\begin{array}{c}\text { Percentage } \\
\text { (\%) }\end{array}$ \\
\hline $\begin{array}{l}\text { Evacuation } \\
\begin{array}{l}\text { Evacuation+phaco } \\
\text { emulsification+IOL }\end{array}\end{array}$ & 24 & $55.84 \%$ \\
$\begin{array}{l}\text { Evacuation+EL } \\
\begin{array}{l}\text { Evacuation+EL+ } \\
\text { phacoemulsifi } \\
\text { cation+lOL } \\
\text { SO exchange+ } \\
\text { vitrectomy+EL }\end{array}\end{array}$ & 3 & $31.16 \%$ \\
Total & 3 & $3.9 \%$ \\
\hline
\end{tabular}

*EL= Endolaser 
There were 4 (5.2\%) cases of retinal redetachment found upon SO evacuation procedure thus needing SO exchange, vitrectomy, and endolaser procedure to be done.

Table 4. Visual Acuity Before and After SO Evacuation

\begin{tabular}{ccc}
\hline Visual Acuity & $\begin{array}{c}\text { Pre } \\
\text { So Injection }\end{array}$ & $\begin{array}{c}\text { One Month } \\
\text { Post SO } \\
\text { Evacuation }\end{array}$ \\
\hline $\begin{array}{c}\text { Loss of Follw } \\
\text { Up }\end{array}$ & - & $9(11.69 \%)$ \\
$1 / 300$ & $26(33.77 \%)$ & $11(14.29 \%)$ \\
$0.5 / 60$ & $19(24.68 \%)$ & $15(19.48 \%)$ \\
$1 / 60-3 / 60$ & $23(29.87 \%)$ & $22(28.57 \%)$ \\
$>6 / 60$ & $9(11.69 \%)$ & $20(25.97 \%)$
\end{tabular}

Changes in visual acuity are described in Table 4. There were 26 patients (33.77\%) who had a visual acuity of $1 / 300$ prior to SO injection. This number decreased at one month post SO evacuation to be only 11 patients (14.29\%). Patients visual acuity $>6 / 60$ increases from 9 patients to 20 patients. There were 9 patients who were lost to follow up.

Table 5. Intraocular Pressure (IOP) Before and After SO Evacuation

\begin{tabular}{ccc}
\hline $\begin{array}{c}\text { Intraocular } \\
\text { Pressure }\end{array}$ & $\begin{array}{c}\text { Pre } \\
\text { So Injection } \\
\text { (n, \%) }\end{array}$ & $\begin{array}{c}\text { One Month } \\
\text { Post SO } \\
\text { Evacuation }\end{array}$ \\
\hline $\begin{array}{c}\text { Loss of } \\
\text { Follow Up } \\
<8\end{array}$ & - & $10(12.98 \%)$ \\
$9-21$ & $13(16.88 \%)$ & $8(10.39 \%)$ \\
$>21$ & $52(67.53 \%$ & $44(57.14 \%)$ \\
& $2(2.59 \%)$ & $15(19.48 \%)$
\end{tabular}

Intraocular pressure (IOP) measurement was done prior to SO injection and post SO evacuation presented on Table 5. Prior to $\mathrm{SO}$ injection, the majority of patients have IOP between $9-21 \mathrm{mmHg} 67.53 \%$ and this number relatively constant after one month post SO evacuation (57.14\%). However, the number of patients who possessed IOP $>21 \mathrm{mmHg}$ increases become 15 patients (19.48\%) (Table 5). 10 patients were lost to follow up or no IOP recorded on the medical record.

Anatomical successability of SO usage was evaluated during SO evacuation procedure and was found to be highly successful retinal reattachment at $91 \%$ of the cases and only $9 \%$ of cases had persisted retinal detachment.

Table 6. Complication Occuring Post SO Evacuation

\begin{tabular}{lcc}
\hline $\begin{array}{c}\text { Complication } \\
\text { After SO } \\
\text { Evacuation }\end{array}$ & $\begin{array}{c}\text { Frequency } \\
\text { (n) }\end{array}$ & Percentage (\%) \\
\hline $\begin{array}{l}\text { Retinal } \\
\text { redetachment }\end{array}$ & 8 & $10.39 \%$
\end{tabular}

$\begin{array}{lcc}\begin{array}{l}\text { Vitreous } \\ \text { hemorrhage } \\ \text { Choroidal } \\ \text { detachment }\end{array} & 3 & 3.8 \% \\ \begin{array}{l}\text { Secondary } \\ \text { Glaucoma }\end{array} & 13 & 1.3 \% \\ \begin{array}{l}\text { Toxic anterior } \\ \text { segment } \\ \text { syndrome }\end{array} & 1 & 16.88 \% \\ \begin{array}{l}\text { (TASS) } \\ \text { Endophthalmit } \\ \text { is }\end{array} & 1 & 1.3 \%\end{array}$

Table 6 records the complication occurring after SO evacuation. The most common complication is secondary glaucoma (16.88\%) followed by retinal redetachment (10.39\%) and vitreous hemorrhage (3.8\%). The three cases of vitreous hemorrhage leads to other complications including retinal redetachment and non-clearing vitreous hemorrhage. Patient who suffered from vitreous hemorrhage and retinal redetachment underwent vitrectomy procedure and SO tamponade. The non clearing vitreous hemorrhage underwent two different treatment approaches vitrectomy combined with endolaser and conservative treatment of semifowler position. Other complication such as choroidal detachment, TASS and endophtalmitis were found only in one patient for each complication.

\section{DISCUSSION}

A descriptive retrospective study was done in 77 retinal detachment in Cipto Mangunkusumo Hospital, Indonesia who underwent SO evacuation to evaluate the outcome of the procedure. On this study, patient's characteristics were found to be predominantly male ages $>50$ years old and had phakic lens. According to Lam et al, those variables tend to vary among healthcare facilities and do not act as a prognostic factor in determining anatomical successability following SO evacuation. ${ }^{14}$

High myopia status found on 18 cases (23.38\%) and one of them experienced retinal redetachment after SO evacuation. Scholda et al found that high myopia state has been associated with higher retinal redetachment following SO evacuation. ${ }^{15}$ Meanwhile, Lam et al studies found the axial length of the eye above $27 \mathrm{~mm}$ is a risk factor for low anatomical successability after a SO evacuation. ${ }^{14}$

Our evaluation recorded the predominant indication for SO evacuation was emulsification and stable retinal reattachment for more than 6 months. This finding is in concordant with a study by Teke et al where emulsification is the most common complication occurring in tamponading with SO. ${ }^{16}$ On the other hand, Choudary et al reported that the main indication for SO evacuation was high IOP. ${ }^{17}$

The available literature regarding the best timing for SO evacuation vary among studies from 8 weeks to 1 year. However, it is strongly suggested to perform evacuation procedure when emulsification is evident or after the stable 
retinal reattachment has occurred and persisted for more than 6 months. ${ }^{18,} 19$ The emulsification of SO triggers inflammation process, induces proliferative vitreoretinopathy, secondary glaucoma, and keratopathy. Moreover, there is not enough evidence that suggest the longer duration of maintaining SO inside the eye leads to a better outcome. ${ }^{20,21}$

There were 24 patients (31.07\%) who underwent SO evacuation combined with phacoemulsification. The high number of this procedure was due to cataract formation. The prolonged contact between SO and the posterior capsule of the lens which triggers epithelial proliferation hence cataract formation. The combination of these procedures has been found to be safe and proven to yield a better visual outcome. 22,23

There was a pronounced improvement in the group of visual acuity $>6 / 60$ within one month post SO evacuation from 9 patients to 20 patients. Furthermore, the number of patients who has visual acuity of $1 / 300$ markedly decreases after the evacuation procedure by 9\%. A study by Goezinne et al reported a $45 \%$ improvement of at least two Snellen lines and 36\% remained stable or improve at least one Snellen lines after SO evacuation. ${ }^{24}$ On contrary, several studies found decreased visual acuity post SO removal from $1-30 \%$ of the cases. This was hypothesized due to neuronal apoptosis triggered by a sudden change in retinal flux ionic, phototoxicity of SO which has the capability to dissolve lutein and zeaxanthin, and retinal toxicity. ${ }^{25-27}$

Elevated IOP $>21 \mathrm{mmHg}$ occurs in 15 (19.48\%) patients post SO evacuation. Meanwhile, Goezinne et al recorded $8.5 \%$ elevated IOP occurs post SO evacuation. ${ }^{24}$ Elevated IOP has been found to be the most common complications in SO usage due to droplets remains obstructing the trabecular meshwork. This study discovered 3 cases of secondary glaucoma which requires surgical therapy including trabeculectomy and or pmma implants. ${ }^{28}$

Hypotonic eyes were also recorded in 8 patients post SO evacuation. Gonvers et al found that this number tends to be higher reaching for $20 \%$ for IOP $1-5 \mathrm{mmHg}$ and $55 \%$ below $11 \mathrm{mmHg} .{ }^{29}$ Hypotonic eyes are associated with choroidal detachment and considered to be a rare case according to Caswell et al. ${ }^{13}$ In this study, there was one case of choroidal detachment with IOP of $11 \mathrm{mmHg}$.

Retinal redetachment is one of complication post SO evacuation. Retinal redetachment can arise due to retinal break as an intraoperative complication or due to the elimination of the SO tamponade. ${ }^{14}$ In our study, 8 retinal redetachment cases were recorded upon SO evacuation. Based on a recent study, the number of retinal redetachment associated with SO evacuation varies from $0-20 \%{ }^{18}$ Meanwhile, Chouldhary et al only report $3.46 \%$ cases of retinal redetachment. The low number in their study is thought due to the advanced surgical technique such as maximum vitreous base shaving, retinotomy, adequate SO tamponade, and laser, hence complication minimization. ${ }^{17}$

Vitreous hemorrhage was reported in 3 eyes (3.8\%). Jonas et al stated that presence of vitreous hemorrhage within 3 days post $\mathrm{SO}$ evacuation is associated with a possible retinal tear or retinal redetachment. ${ }^{30}$ The three cases of vitreous hemorrhage underwent different therapy approach including conservative semi-fowler position, vitrectomy, and vitrectomy with SOI tamponade.

Other complication documented in this study includes endophthalmitis and toxic anterior segment syndrome (TASS) which each accounts for $1.3 \%$. Endophthalmitis occurred 4month post SO evacuation and was treated with evisceration. Meanwhile, the patient with TASS was found to suffer from macular edema and was treated with oral methylprednisolone and triamcinolone acetonide intravitreal injection. TASS was commonly found in the patient who underwent a surgical procedure on anterior segment such as cataract surgery, hence a combination of SO evacuation with phacoemulsification could be the triggering factors for anterior segment inflammation. ${ }^{31}$ However, Moisseiev et al argue that the use of SO triggers inflammation reaction at the anterior segment of the eye. ${ }^{32}$

\section{CONCLUSION}

Evacuation of SO is a standard procedure following SO injection. The procedure results in an improvement of visual acuity and also normal intraocular pressure. However, the patient should be regularly monitored post-evacuation procedure to minimize the complication.

\section{ACKNOWLEDGEMENT}

The author would like to express his gratitude to all parties who have aided the making of this manuscript.

\section{REFERENCES}

1 .Cibis PA, Becker B, Okun E, Canaan S. The use of liquid silicone in retinal detachment surgery. Arch Ophthalmol. 1962;68:590-9.

2. Haut J, Ullern M, Van Effenterre G, Chermet M. [Use of intraocular silicone in 200 cases]. Bull Soc Ophtalmol Fr. 1979;79(8-9):797-9.

3. Castellarin A, Grigorian R, Bhagat N, Del Priore L, Zarbin MA. Vitrectomy with silicone oil infusion in severe diabetic retinopathy. Br J Ophthalmol. 2003;87(3):318-21.

4. Schwartz SG, Flynn HW, Jr., Lee WH, Wang X. Tamponade in surgery for retinal detachment associated with proliferative vitreoretinopathy. Cochrane Database Syst Rev. 2014(2):CD006126.

5. Shen YD, Yang CM. Extended silicone oil tamponade in primary vitrectomy for complex retinal detachment in proliferative diabetic retinopathy: a long-term follow-up study. Eur J Ophthalmol. 2007;17(6):954-60. 
6. Shunmugam M, Ang GS, Lois N. Giant retinal tears. Surv Ophthalmol. 2014;59(2):192-216.

7. Hans-Heinrich Moretto MS, Gebhard Wagner. Silicones. Ullmann's Encyclopedia of Industrial Chemistry. 7 ed2000.

8. Saxena S MC, Ohji M, Akduma L. Long-term intraocular tamponade with silicone oil. Vitreoretinal Surgery. 2012;p.64.

9. Vitrectomy with silicone oil or perfluoropropane gas in eyes with severe proliferative vitreoretinopathy: results of a randomized clinical trial. Silicone Study Report 2. Arch Ophthalmol. 1992;110(6):780-92.

10. Vitrectomy with silicone oil or sulfur hexafluoride gas in eyes with severe proliferative vitreoretinopathy: results of a randomized clinical trial. Silicone Study Report 1. Arch Ophthalmol. 1992;110(6):770-9.

11. Federman JL, Schubert HD. Complications associated with the use of silicone oil in 150 eyes after retina-vitreous surgery. Ophthalmology. 1988;95(7):8706.

12.Franks WA, Leaver PK. Removal of silicone oil-rewards and penalties. Eye (Lond). 1991;5 ( Pt 3):333-7.

13. Casswell AG, Gregor ZJ. Silicone oil removal. II. Operative and postoperative complications. $\mathrm{Br} \mathrm{J}$ Ophthalmol. 1987;71(12):898-902.

14. Lam RF, Cheung BT, Yuen CY, Wong D, Lam DS, Lai WW. Retinal redetachment after silicone oil removal in proliferative vitreoretinopathy: a prognostic factor analysis. Am J Ophthalmol. 2008;145(3):527-33.

15. Scholda C, Egger S, Lakits A, Walch K, von Eckardstein E, Biowski R. Retinal detachment after silicone oil removal. Acta Ophthalmol Scand. 2000;78(2):182-6.

16. Teke MY, Balikoglu-Yilmaz M, Yuksekkaya $P$, Citirik $M$, Elgin $U$, Kose $T$, et al. Surgical outcomes and incidence of retinal redetachment in cases with complicated retinal detachment after silicone oil removal: univariate and multiple risk factors analysis. Retina. 2014;34(10):1926-38.

17. Choudhary MM, Choudhary MM, Saeed MU, Ali A. Removal of silicone oil: prognostic factors and incidence of retinal redetachment. Retina. 2012;32(10):2034-8.

18. Hutton WL, Azen SP, Blumenkranz MS, Lai MY, McCuen BW, Han DP, et al. The effects of silicone oil removal. Silicone Study Report 6. Arch Ophthalmol. 1994;112(6):778-85.

19. Jonas JB, Budde WM, Knorr HL. Timing of retinal redetachment after removal of intraocular silicone oil tamponade. Am J Ophthalmol. 1999;128(5):628-31.

20. Scholda C, Egger S, Lakits A, Haddad R. Silicone oil removal: results, risks and complications. Acta Ophthalmol Scand. 1997;75(6):695-9.
21. K J. Retinal Redetachment after Silicone Oil Removal Pak J Opthalmol.28:127-31.

22. Loncar VL, Petric I, Vatavuk Z, Bencic G, AndrijevicDerk B, Mandic Z. Phacoemulsification and silicone oil removal through the planned posterior capsulorhexis. Coll Antropol. 2005;29 Suppl 1:63-6.

23. Krepler K, Mozaffarieh M, Biowski R, Nepp J, Wedrich A. Cataract surgery and silicone oil removal: visual outcome and complications in a combined vs. two step surgical approach. Retina. 2003;23(5):647-53.

24. Goezinne F, La Heij EC, Berendschot TT, Liem AT, Hendrikse F. Risk factors for redetachment and worse visual outcome after silicone oil removal in eyes with complicated retinal detachment. Eur J Ophthalmol. 2007;17(4):627-37.

25. Roca JA, Wu L, Berrocal M, Rodriguez F, Alezzandrini A, Alvira $G$, et al. Un-explained visual loss following silicone oil removal: results of the Pan American Collaborative Retina Study (PACORES) Group. Int J Retina Vitreous. 2017;3:26.

26. Newsom RS, Johnston R, Sullivan PM, Aylward GB, Holder GE, Gregor ZJ. Sudden visual loss after removal of silicone oil. Retina. 2004;24(6):871-7.

27. Kirchhof B, Tavakolian U, Paulmann H, Heimann K. Histopathological findings in eyes after silicone oil injection. Graefes Arch Clin Exp Ophthalmol. 1986;224(1):34-7.

28. Ni C, Wang WJ, Albert DM, Schepens CL. Intravitreous silicone injection. Histopathologic findings in a human eye after 12 years. Arch Ophthalmol. 1983;101(9):1399-401.

29. Gonvers M. Temporary silicone oil tamponade in the management of retinal detachment with proliferative vitreoretinopathy. Am J Ophthalmol. 1985;100(2):239-45.

30. Jonas JB, Knorr HL, Rank RM, Budde WM. Retinal redetachment after removal of intraocular silicone oil tamponade. Br J Ophthalmol. 2001;85(10):1203-7.

31. Cetinkaya S, Dadaci Z, Aksoy H, Acir NO, Yener HI, Kadioglu E. Toxic anterior-segment syndrome (TASS). Clin Ophthalmol. 2014;8:2065-9.

32. Moisseiev E, Barak A. Toxic anterior segment syndrome outbreak after vitrectomy and silicone oil injection. Eur J Ophthalmol. 2012;22(5):803-7.

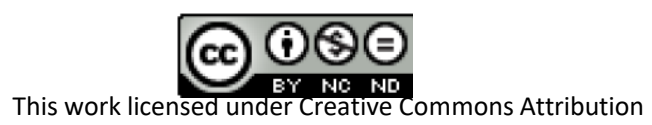

